\title{
The piloting of an Academic Literary Education Course (ALEC) to improve academic literacy of first semester undergraduate students in a Western Australian university
}

\author{
Joyce Hendricks ${ }^{1}$, Lesley Andrew ${ }^{2}$, Amanda C Fowler ${ }^{1}$ \\ 1. School of Nursing and Midwifery, Edith Cowan University, Perth, Australia. 2. School of Exercise and Health Sciences, \\ Edith Cowan University, Perth, Australia.
}

Correspondence: Joyce Hendricks. Address: 270 J oondalup Drive, Joondalup, Australia. Email: j.hendricks@ecu.edu.au

Received: September 16, 2013 Accepted: October 21, $2013 \quad$ Online Published: November 26, 2013

DOI : 10.5430/jnep.v4n4p19 URL: http://dx.doi.org/10.5430/jnep.v4n4p19

\begin{abstract}
Widening participation has enabled access to higher education for an increasing number of students via a range of non-traditional pathways. Consequently, whilst having a large repertoire of skills and experience, these students may not have developed sufficient competence in academic literacy. The School of Nursing and Midwifery has a large proportion of such students who have difficulty making the academic transition to university study.

It is believed that a 'built in' approach to supporting these students to develop academic literacy will result in an improvement in their abilities to meet the requirements of the University and to better prepare them to graduate.

This paper discusses the piloting of an Academic Literary Education Course (ALEC) for undergraduate students enrolled in the first semester unit of a three year health degree, within the disciplines of nursing and paramedical science. The students completed tests on academic literacy before and after completion of the ALEC. Particular areas of difficulty for students were found to be in referencing and unpacking the assessment question. When mean scores were compared between pre and post-tests in the same group, it was found there was a significant difference between scores at $t$ value $=$ $-7,721$, degrees of freedom $=181$ with a $p$ value of 0.000 or $p$ value $<.001$. Recommendations include incorporating the ALEC approach in further stages of the undergraduate degree program to support developing levels of academic literacy.
\end{abstract}

\section{Key words}

Undergraduate, Higher education, Academic literacy education course, Non-traditional

\section{Introduction}

Widening participation in higher education, a key objective of educational policy in Australia ${ }^{[1]}$, is an important focus for universities that have a student cohort drawn from a diverse range of social and cultural groups. There is also an increasing role being played by non- traditional entry methods. Smit ${ }^{[2]}$ defines non-traditional students as diverse in terms of age, education, class, language and cultural backgrounds. They are often from lower socio-economic groups and some have English as an additional language. Many have not yet acquired the necessary literacy, numeracy and academic 
skills crucial to succeeding in higher education. The Gonski Report (2011) in Australia, asserts that there is an unacceptable link between low levels of achievement and educational disadvantage, particularly among students from low socioeconomic and Indigenous backgrounds and acknowledges that many students leave school without the basic skills and competencies needed to participate in the workforce and lead successful and productive lives ${ }^{[3]}$. This unpreparedness is also evident at the university.

Increasingly, instead of blaming the school system for the degree of preparedness of students, universities and other institutions of higher education recognise this as an issue within their own remit. To meet this challenge there is a greater focus on intervention strategies, often in the form of academic literacy classes to assist students to meet the academic rigor of university-based programmes. This needs attention before students can attempt to meet the professional competence of a chosen career. Weidman ${ }^{[4]}$ contends that whilst it may be accepted that ability in the language or languages of instruction and learning, is not the only factor that contributes to poor student performance, poor language ability remains a very important obstacle. Interestingly, Harris and Ashton ${ }^{[5]}$ attest that not only do universities contend with lower literacy rates of domestic students, they also attract a high percentage of international students, for whom many identify English as an additional language. These factors have a direct influence on student success and subsequent attrition rates. Taylor ${ }^{\text {[15] }}$ comments that in Australia a quarter of students enrolled in undergraduate at any one time will not persist with their studies. The attrition of students studying at a distance may be even higher, with many students withdrawing prior to attempting their first assignment. The financial implications incurred from attrition are important incentives to improve academic support by higher education providers ${ }^{[6]}$.

The aim of this paper is to explore the development, delivery and evaluation of a pilot academic literacy education course (ALEC) to assist students commencing a Bachelor of Science (Nursing) degree make a successful transition to university study in semester one at Edith Cowan University (ECU) in Western Australia.

\section{Background}

The Bachelor of Science (Nursing) undergraduate student cohort is comprised of a diversity of student demographics, with many students taking advantage of the flexible admission routes offered by the University. These admission routes are also offered by other Australian universities. In 2011 at ECU, 69\% of student enrolments accessed courses by a variety of routes other than direct school leaver entry; including 25\% via approved Training and Further Education (TAFE) course qualifications. A further $6 \%$ of students gained entry to university through the successful completion of the Mature Age Special Tertiary Admissions Test (STAT), 17\% of students were able to demonstrate the completion of previous tertiary education, and 21\% from other routes (such as university preparation courses and portfolio outlining prior learning and experience) ${ }^{[7]}$. Whilst this equitable approach ensures a rich balance of student experience and contribution to the nursing learning environment, a less discussed consequence is that a large number of students may begin their university journey with limited academic literacy skills which are essential to the successful completion of undergraduate study.

Not only do nursing students need to meet the University agenda of rigour in academic literacy, future nurses must also meet the requirements of a registering authority and the service needs of the profession. The day to day work of nurses requires sound verbal and written communication skills. With a larger number of students from non-traditional educational backgrounds being attracted to nursing a consequence is that these students may require support and assistance in literacy to meet the criteria for successful completion of the course and to meet the demands for employability. Salamonson and colleagues ${ }^{[8]}$ state that it has "been shown to be particularly important in health science courses such as nursing, where there is a demand for specific nursing content language to be communicated in clinical settings"(p.413). This concern is recognised by the Australian Universities Quality Agency (AUQA) which stresses that both widening participation and the increase in international students means it can no longer be assumed that university students enter tertiary education with English language skills at a level needed for successful engagement in their course studies ${ }^{[9]}$. English language proficiency for all students is therefore an essential aspect of academic literacy. 
Academic literacy is a term used to describe “...all forms of communication, reading, writing and spoken”(p.2) ${ }^{[10]}$. Furthermore, Chu and colleagues ${ }^{[11]}$ contend that "academic literacy refers to the critical thinking, reading, writing, speaking and listening skills required by a scholarship community”(p.77).

Weidman ${ }^{[4]}$ asserts that a student who is academically literate should be able to: use academic vocabulary; interpret and use; understand and be aware of the logical development of (an academic) text, via introductions to conclusions, and know how to use language; show sensitivity for the meaning conveyed, and the intended audience; interpret, use and produce information presented in graphic or visual format; make distinctions between essential and non-essential information, fact and opinion, propositions and arguments; distinguish between cause and effect, classify, categorise and handle data that make comparisons and can be applied for the purposes of an argument; know what counts as evidence for an argument, extrapolate from information by making inferences, and apply the information, or its implications to other cases than the one at hand; understand the communicative function of various ways of expression in academic language (such as defining, providing examples, arguing); and make meaning (e.g. of an academic text) beyond the level of the sentence (p.2).

Murray ${ }^{[12]}$ claims, that during the employment period employers place communication and language abilities as essential employee requisites. Murray goes on to argue that "academic literacy is something with which few if any students, domestic or international English Speaking Background (ESB) or NESB (Non English Speaking Background), enter university adequately equipped"(p.351). The academic nursing staff, who taught in the course, corroborated with Murray's findings noting the student's poor understanding and application of academic literacy skills. In particular, when required to undertake a written assessment, students lacked the ability to structure and reference an essay.

It should be mentioned that, despite the School of Nursing and Midwifery having an excellent academic learning advisor team, who already provided academic support programmes at induction and throughout each semester, there remained a significant proportion of students who did not voluntarily access the service. Students often cited reasons related to late enrolment and time constraints that limited attending additional support writing classes. Some students lacked an insight into personal needs and ability deficits until assessment feedback had been given; and, academic staff referred the student for one to one support. Attendance, however, remained voluntary or time lags to visiting an advisor occurred because the service was highly subscribed. Thus, referral to the academic advisors became insufficient and reactive. Wingate ${ }^{[13]}$ Chanock ${ }^{[14]}$ Salamonson and colleagues ${ }^{[8]}$ argue these 'bolt-on' practices are 'remedial', and do not assist the student in the context of 'real' assessment and disciplinary subject matter unless skills are embedded, and an integral part of a course.

In a response to these issues, many universities, including ECU, are now embedding transition skills in curriculum $\operatorname{design}^{[8,15-17]}$.

\section{The development of the ALEC pilot}

An annual review of student assessment outcomes, undertaken by a first year student experience interest group, revealed many students did not demonstrate an awareness of the expectations of writing at undergraduate level. First year students repeatedly made errors in referencing, essay construction and paraphrasing which impacted upon academic integrity, resulting in stalling in course progress and often an ultimate failure and exclusion from the course.

Concerned academic staff, along with the School's Academic Learning Advisors, acknowledged that a collaborative approach was needed to support students, subscribing to the advice given by Murray ${ }^{[12]}$ that:

Literacies [that students] require for higher education need to be learned, and learned within the context of their discipline area, embedded within the curriculum and presented as an integral part of their undergraduate studies where they take on an immediacy, relevance, and authenticity (p. 351). 
With this sentiment in mind, ALEC was embedded in all first semester units to support students. Most importantly, it was decided that ALEC would be marketed as a positive learning opportunity for all students to be credited with achievement, with a Smart ALEC certificate on completion, rather than as a punitive requirement of students who had been identified as failing.

\section{Academic Literacy Education Course (ALEC)}

Ten learning modules were written related to referencing, essay construction, and paraphrasing. Specifically, modules covered: analysing the question, essay preparation, planning, structure, paraphrasing, sourcing information, referencing, using quotations, critical thinking skills and plagiarism. Modules were interactive with assessed aspects of the ALEC giving immediate feedback to students by stating whether answers were correct. To further assist learning, answers were given with a full and clear comprehensive reason as to why the response was correct or incorrect.

Each module incorporated a range of learning opportunities, using a blended approach of case studies, exemplars and video links. The focus of modules ensured that academic expectations and processes were unambiguous as this has been found to be a key challenge to improving academic literacy for students ${ }^{[18]}$. For example, an assessment terminology guide was provided that gave clear explanations of commonly used terms such as 'analyse' 'define' 'compare/contrast' and 'evaluate'. These terms were then incorporated into assessed learning opportunities. The learning activities were contextualised to a range of nursing situations for example: describe and discuss cultural competency or compare and contrast two lifespan development theories. This was recognised as an important part of authenticating learning for students ${ }^{[19]}$.

ALEC was made available through the online Blackboard 9 learning platform. Only first year, semester one students enrolled in an on-campus core unit Communication in Health Care were given access. Students were orientated to the Blackboard site with in the first two weeks of the unit. Students were able to self-pace their learning, thereby those who had work and family commitments were provided with flexible time frames to work through the modules, thus not being disadvantaged. Further, following discussion with the first year student experience interest group and learning advisors, the successful completion of ALEC modules was incorporated into the summative assessment of the unit. The students were required to pass this programme in order to pass the unit. Students were given an ALEC certificate on completion. To reinforce the learning of concepts within ALEC all nursing theory units in semester one had $20 \%$ of any written assessment allocated to demonstrate academic literacy.

\section{Research design}

The ALEC was piloted in 2011 for commencing students in the unit Communication in Health Care (NPP1101). In order to ascertain the impact it had on student learning a descriptive exploratory study with a pre and post-test was undertaken.

\section{Research question}

Did the completion of the ALEC programme demonstrate the improvement from pre to post test of identified academic criteria.

\section{Selection of participants}

All on-campus students enrolled in the unit Communication in Health Care (NPP1101) in semester one of the course provided a convenience sample, $\mathrm{n}=214$. One hundred and forty-three were nursing students and 71 students of paramedicine.

\section{Data collection}

Data were collected through pre and post- tests to rate their understanding of key criteria related to referencing, essay construction, academic integrity (plagiarism) and paraphrasing. Students completed the pre-test on day one of the unit, and 
a post-test occurred in week nine of the semester. The test comprised of twenty multiple choice questions across the range of academic literacy as described above. The tests were conducted under exam conditions at the university and were paper based. The content of the programme modules and the tests were reviewed by six subject matter experts to establish face validity prior to programme launch. Following the pre-test, students were required to undertake the ALEC programme through Blackboard 9.

The Statistical Package for the Social Sciences 19 (SPSS) was used for data analysis. This project was funded by the Edith Cowan University's Learning and Teaching Committee and ethics approval was obtained from the Edith Cowan University Ethics Committee.

\section{Results}

At the pre-test 214 students were enrolled in the unit. 197 (92.05\%) students undertook the assessment. 17 (7.94\%) students were excluded from the data if they could not be identified from the test papers.

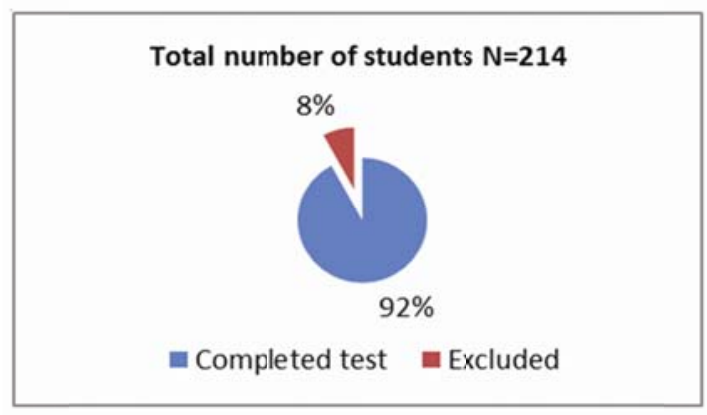

Figure1. Percentage of enrolled students in the unit at pre-test

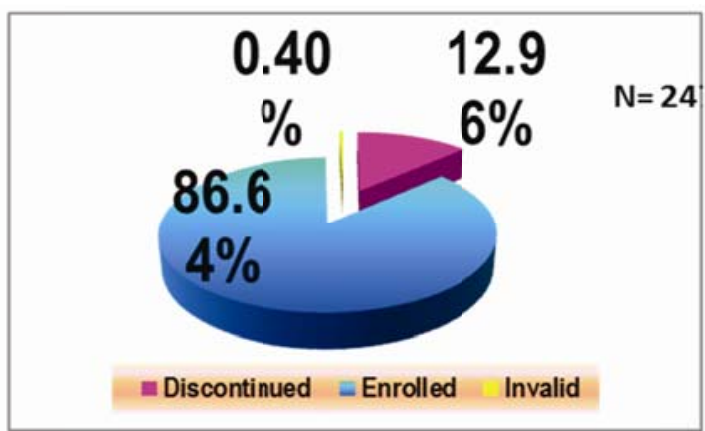

Figure 2. Percentage of enrolled students in the unit at post-test

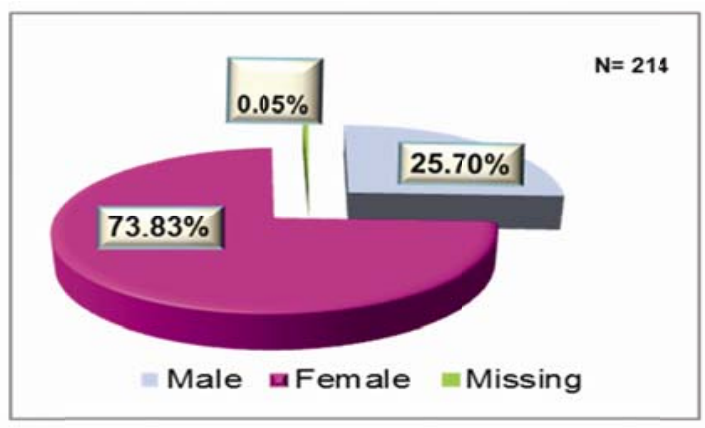

Figure 3. Percentage of students by gender at post-test 
73.83\% of students at post-test were female, $25.70 \%$ male and $0.05 \%$ did not fill in gender. The large number of males reflects the inclusion of paramedic students in the unit of study.

At post-test, 191 (89.25\%) of the original 214 students enrolled participated in this assessment, 23 (10.75\%) did not take part in the assessment, 6 of whom were lost through attrition. A further 9 students were excluded from data analysis because they were unable to be identified. Finally, the statistical analyses, paired $t$ test, were based on the data from 182 students. An attrition rate of $0.32 \%$ occurred over time.

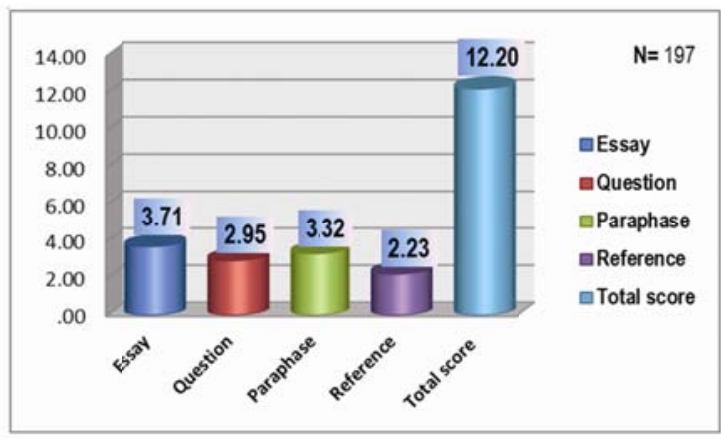

Figure 4. Mean scores for each skill and total scores pre-test.

The pass rate for each of the sections of the test and test in total were set at 50\%. The overall mean score for the group was 12.20 out of a total score of 20 at pre-test (61\%). Students scored most poorly in questions relating to referencing (2.23/5) and best in questions relating to essay planning and structure (3.71/5). Difficulty was also noted in the section of the test related to unpacking the question. Interestingly, students did slightly better in the section of the test concerned with paraphrasing (3.32/5).

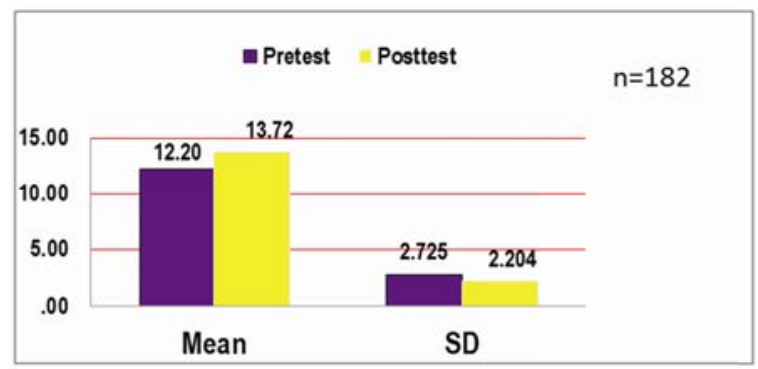

Figure 5. Comparison between mean and SD of pre and post-test.

The overall score at post-test improved from the pre-test by $1.52(7.6 \%)$ to $69 \%$. When mean scores were compared between pre and post-tests, in the same group, it was found that there was a significant difference between these pre and post-test scores at $t$ value $=-7,721$, degrees of freedom $=181$ with a $p$ value of 0.000 or $p$ value $<.001$.

\section{Discussion}

The ECU student cohorts undertaking the ALEC are representative of students who enter by non-traditional entrance pathways; and, therefore the academic literacy problems identified were not surprising. This supports the work of Glaser and colleagues ${ }^{[20]}$ who found that half the college students in the USA did not meet the standards that would prepare them for higher education level.

The results of this study highlight areas of student needs in academic literacy and support the literature indicating that many students enter university with a command of academic literacy which may not be congruent with the rigour required. 
The learning content included in the ALEC was justified by the pilot test findings which identified deficits in these fundamental academic areas. In particular, it was demonstrated that students required more information and education in the areas of correct referencing, paraphrasing and unpacking essay questions. These deficits are discussed below.

The students in this study demonstrated weaknesses in referencing and paraphrasing. This is not a new problem for students. Neville ${ }^{[21]}$ found that students show problems in using citation as evidence for supporting their own ideas in their writing and making clear linguistic distinctions between views from the literature. The implications of not addressing these problems in the early stages may lead to student inadvertent plagiarism. Vardi ${ }^{[22]}$ states that when student use plagiarism it is of grave concern to academic staff and the university because and is presented of unethical practice. Furthermore studies ${ }^{[23,24]}$ have found that in the beginning stages of academic work students often create 'Frankenstein' papers that are poorly referenced and reworded therefore losing the context and flow which Shi ${ }^{[23]}$ refers to 'patch writing'. This problem is compounded for students who have English as an additional language and also have underdeveloped paraphrasing skills who mistakenly replace words with inappropriate synonyms in an attempt to avoid plagiarism. Moreover, Maher ${ }^{[25]}$ asserts that learners whose first language is not English but are taught and assessed in English not only have to contend with learning new and advanced subject matter but also learning this material in a different language to their mother tongue.

Another area of difficulty identified was the students' ability to 'unpack the question'. This term refers to the student being able to understand what their tutor is asking of them and being able to articulate an appropriate answer. This inability is significant for students because the consequence of not answering the question results in losing marks, sometimes resulting in assessment failure. Kenny and colleagues ${ }^{[26]}$ highlight the importance of making terms and instructions explicit for non-traditional students. It may be contended that the use of explicit instructions and the definition and breakdown of essay components to manageable 'chunks' will assist students in planning and structuring essays.

Interestingly, despite difficulties in the ability to unpack the question, students did better in essay construction and planning. This may be a consequence of students' ability to use the concrete essay writing skills learnt at school prior to commencing higher education. In contrast, the advanced analytical skills necessary for the areas of academic literacy in which the students performed less well requires an ability to work with abstract and sometimes unrelated concepts to develop relationships. Students in the first semester at university are not only new to disciplinary content, but are often expected to make a great leap in their ability to conceptualise and work as independent learner whilst they are still working to a didactic model which may require less abstraction and therefore lower order academic ability and thinking. Hammer and Green ${ }^{[27]}$ have found that students construct (and reconstruct) their knowledge as they progress through their undergraduate degree. Whilst the post test scores in this study indicated significant improvement, they also revealed a continuing deficit of ability in these higher order areas of academic literacy. An approach such as the ALEC would therefore have ongoing value throughout the undergraduate course, to support this student learning process of developing this essential ability.

The ALEC, in including all students within its programme, was a proactive approach which did not rely on singling out individual failing students. The previous approach used by the School in which only students who were identified as struggling were referred to individual academic support sessions could be construed as being demotivating and unhelpful as “... further marginalising of already vulnerable individuals...”(p.344 ${ }^{[12]}$. The flexibility of the ALEC enabled students the options of learning in group environment, or through individual study. This allowed the programme to be tailored to student preferences and avoided a one 'fix' for all approach. Smit ${ }^{[2]}$ maintains that "employing a 'fix' mindset to problematise student academic literary deficits "perpetuates stereotypes, alienates students from higher education and disregards the role of higher education in perpetuating the barriers to student success”(p.369).

The ALEC used a team approach between lecturers and academic advisors in designing and implementing the programme. Dunworth ${ }^{[28]}$ Gimenez ${ }^{[29]}$ Huijser, Kimmins and Galligan ${ }^{[30]}$ Salamonson and colleagues ${ }^{[8]}$ state that this integrative 
approach has been found to be successful in building students' academic literacy. The team involved in this study found the sharing of skills, knowledge and experience to be invaluable to the development of a meaningful and accessible programme.

\section{Limitations of the study}

This was a single site pilot study and therefore the generalisability of results is limited. Although the statistical significance between pre and post test scores suggests that the programme is valuable in supporting students' academic development. It is also not clear if the improvement can be solely attributed to the ALEC as researchers did not control for other variables. This limitation will be addressed in the next study related to ALEC.

\section{Recommendations from the study}

With the widening diversity of students entering the university, and in particular for universities that have a culture of inclusivity the embedding of an academic literacy programme is necessary to ensure equity of opportunity and success $^{[8,17]}$. Also, an improvement in a student's literacy, at any level, increases their employability and fitness to practice as a health professional. The study highlights the importance of the continued embedding of the ALEC throughout year one for all students.

\section{Conclusion}

Universities are challenged by increasing diversity of students, many who are unprepared for university study. This pilot study has demonstrated a statistically significant improvement in student academic literacy after the undertaking ALEC, and supports the need to have an academic literacy programme embedded in the foundation units of study, using an integrative approach. There is a growing realisation that supporting academic literacy skills is a central issue for consideration across all areas of higher education, and in particular, vocational and service based degree courses that lead to professional registration. This also assists in meeting the challenges brought by the diverse group of students entering from non-traditional backgrounds.

\section{References}

[1] Review of Australian Higher Education - The Bradley Review, Review of Australian Higher Education - The Bradley Review, 2008, The University of Melbourne Submission.

[2] Smit, R., Towards a clearer understanding of student disadvantage in higher education: problematising deficit. Higher Education \& Research Development. 2012; 31(3): 369-380. http://dx.doi.org/10.1080/07294360.2011.634383

[3] Gonski, D., Review of Funding for Schooling, in Final Report. 2011, Australian Government: Canberra.

[4] Weidman, A., Assessing academic literacy in a task-based approach. Language matters. 2006; 37(1): 81-101.

[5] Harris, A. and J. Ashton, Integrating academic and language skills within management units, in Teaching and Learning Forum 2011.

[6] James, R., K.L. Krause, and C. Jennings. The First Year Experience in Australian Universities: Findings from 1994 to 2009. 2010; Available from: http://www.cshe.unimelb.edu.au/research/experience/docs/FYE_Report_1994_to_2009.pdf.

[7] Edith Cowan University, Entry pathways for Bachelor of Science (Nursing) degree K45, 2012, Perth WA.

[8] Salamonson, Y., et al., Embedded academic writing support for nursing students with English as a second language. Journal of Advanced Nursing. 2010; 66(2): 413-421. PMid:20423424 http://dx.doi.org/10.1111/j.1365-2648.2009.05158.x

[9] Australian University Quality Agency, Report of an Audit of Macquarie University, in AUQA Audit Report2009.

[10] Short, D. and S. Fitzsimmons, Double the work: Challenges and solutions to acquiring language and academic literacy for adolescent English language learners 2007, Alliance for Excellent Education: Carnegie Corporation of New York, Wahington DC.

[11] Chu, C., A. Perkins, and D. Marks-Maran, Delivering a transition programme in literacy from level 4 to level 5 for nursing students: A pilot study. Nurse Education in Practice. 2012; 12(2): 77-82. PMid:21835697 http://dx.doi.org/10.1016/j.nepr.2011.07.006

[12] Murray, N., Considerations in the post-enrolment assessment of English language proficiency: reflections from the Australian context. Language Assessment Quarterly. 2010; 7: 343-358. 
[13] Wingate, U., Doing away with 'study skills'. Teaching in Higher Education. 2006; 11(4): 457-64. http://dx.doi.org/10.1080/13562510600874268

[14] Chanock, K., What academic language and learning advisers bring to the scholarship of teaching and learning: problems and possibilities for dialogue with the disciplines. Higher Education Research \& Development. 2007; 26(3): 269-280. http://dx.doi.org/10.1080/07294360701494294

[15] Taylor, A., Assessment in First Year University: A Model to Manage Transition. Journal of University Teaching \& Learning Practice. 2008; 5(1): 1-17.

[16] Cluett, L. and J. Skene, More than the sum of its parts: Provision of Learning and Academic Skills services through a centralised model, 2006, University of Western Australia, Teaching and Learning Forum.

[17] Cameron, H., Focusing feedback to better engage first year students, in First Year in Higher Education Conference 2008: Hobart Tasmania.

[18] Tinto, V., Taking student retention seriously. Rethinking the first year of university. 2009.

[19] Krause, K., L. and H. Coates, Students' engagement in first year university. Assessment and Evaluation in Higher Education. 2008; 33(5): 493-505. http://dx.doi.org/10.1080/02602930701698892

[20] Glaser, B., M. Leur, and M. Grant, Changing teacher beliefs about promoting literacy in content area classes. Research in Higher Education Journal. 2012; 16: 1-7.

[21] Neville, C., Referencing: Principles, Practice and Problems. RGUHS Journal of Pharmacology Science. 2012; 2(2): 1-8.

[22] Vardi, I., Developing students referencing skills: a matter of plagiarism, punishment and morality or of learning to write critically. Higher Education Research \& Development. 2013; 31(6): 921-930.

[23] Shi, L., Textual Appropriation and Citing Behaviors of University Undergraduates. Applied Linguistics. 2010; 31(1): 1-24. http://dx.doi.org/10.1093/applin/amn045

[24] Elander, J., et al., Evaluation of an intervention to help students avoid unintentional plagiarism by improving their authorial identity. Assessment \& Evaluation in Higher Education. 2009; 35(2): 157-171.

[25] Maher, C., Academic writing ability and performance of first year university students in South Africa, 2011, University of the Witwatersrand.

[26] Kenny, A., et al., Mature age students access, entry and success in nurse education: An action research study. Contemporary Nurse. 2011; 38(1-2): 106-118.

[27] Hammer, S.J. and W. Green, Critical thinking in a first year management unit: the relationship between disciplinary learning, academic literacy and learning progression. Higher Education Research \& Development. 2011; 30(3): 303-315. http://dx.doi.org/10.1080/07294360.2010.501075

[28] Dunworth, K., Clothing the emperor; addressing the issue of English language proficiency in Australian universities. Australian Universities' Review. Australian Universities' Review. 2010; (2): 5-10.

[29] Gimenez, J., Beyond the academic essay: discipline-specific writing in nursing and midwifery. Journal of English for Academic Purposes. 2008; 7(3): 151-164. http://dx.doi.org/10.1016/j.jeap.2008.03.005

[30] Huijser, H., L. Kimmins, and L. Galligan, Evaluating individual teaching on the road to embedding academic skills. Journal of Academic Language and Learning. 2008; 2(1): A23-A38. 